|| ISSN(online): 2589-8698 || ISSN(print): 2589-868X || International Journal of Medical and Biomedical Studies

Available Online at www.ijmbs.info

PubMed (National Library of Medicine ID: 101738825)

Index Copernicus Value 2018: 75.71

Original Research Article

Volume 3, Issue 5; May: 2019; Page No. 232-239

\title{
ASSESSMENT OF PERFORATER SPARING GLUTEAL FASCIOCUTANEOUS FLAP FOR SACRAL PRESSURE SORE
}

\section{Dr. Shyam Kumar Satyapal}

Senior Consultant, Department of Plastic Surgery, Pulse Emergency Hospital, Patna, Bihar, India.

Article Info: Received 05 April 2019; Accepted 30 May. 2019

DOI: https://doi.org/10.32553/ijmbs.v3i5.294

Corresponding Author: Dr. Shyam Kumar Satyapal

Conflict of interest: No conflict of interest.

\section{Abstract:}

Despite advances in reconstruction techniques, sacral pressure ulcers continue to present a challenge to the plastic surgeon.

Fasciocutaneous flaps are tissue flaps that include skin, subcutaneous tissue and the underlying fascia. Including the deep fascia with its prefascial and subfascial plexus enhances the circulation of these flaps. They can be raised without skin and are then referred to as fascial flaps. The present study was planned to evaluate the perforater Sparing Gluteal Fasciocutaneous flap for Sacral pressure sore.

The rotation Gluteal Fasciocutaneous flap for sacral pressure sore coverage have distinct advantage of rotation in the event of ulcer recurrence. The flap from the gluteal crease derives blood supply from the inferior gluteal artery perforator (IGAP) and reliably preserves the entire contralateral side as a donor site.

The author describe their approach of preserving and incorporating musculocutaneous perforators into the conventional rotation design.Data from 11 patients ( 8 men, 3 women; mean age [range 24-71] years old) whose sacral ulcers were closed with an IGAP flap between from Jan 2017 to Apr 2018 June were retrieved and reviewed. All patients were bedridden; 1 patient in a vegetative state with a diagnosis of Cerebro vascular accident was referred from a local clinic, 2 patients had pelvic bone fracture on long duration traction, and 2 patients had a history of Cervical injury leading to quadriplegia, and 6 patient have hemiplegia due to spinal injury. The average defect size was $110 \mathrm{~cm}(2)$ (range $78-134$ $\mathrm{cm}(2))$. The average flap size was $75.8 \mathrm{~cm}(2)$ (range $46-111 \mathrm{~cm}(2)$ ).

After surgery, the patients' position was changed every 2 hours; patients remained prone or on their side for approximately 2 weeks until the flap was healed. After healing was confirmed, patients were discharged. Complications were relatively minor and included 1 donor site wound dehiscence that required wound reapproximation. No surgery-related mortality was noted; the longest follow-up period was 24 months.

The present study was planned in the Department of Plastic Surgery, Pulse Emergency Hospital, Patna, Bihar. Total 11 cases of the operated from Jan 2017 to Apr 2018 were included in the present study. All the patients were informed consents. The aim and the objective of the present study were conveyed to them. Approval of the institutional ethical committee was taken prior to conduct of this study.

The data generated from the present study concludes that the modified method we proposed is relatively simple and easy for reconstructing sacral sores, provides sufficient padding, and has little donor-site morbidity. Once sufficient padding is established in cases like this, a takeaway from this report would be to study the recurrence rates compared with the classic fasciocutaneous flap.

Keywords: Fasciocutaneous flaps, Sacral pressure, sore, etc.

\section{Introduction}

Managing sacral pressure ulcers is a common problem for reconstructive surgeons. Local flaps created from the gluteal region are preferred when wound closure is needed due to their reliability and short learning curve for surgeons. Gluteal muscle perforator-based flaps have been used to cover sacral defects for more than 10 years. This flap construct has become increasingly popular because of its versatility and low incidence of donor site complications.1-3.

The perforator-preserving gluteal artery-based rotation fasciocutaneous flap is a reliable, reusable flap that provides rich vascularity facilitating wound healing and accommodating the difficulties of pressure sore reconstruction. The rotation Gluteal 
Fasciocutaneous flap for sacral pressure sore coverage have distinct advantage of rotation in the event of ulcer recurrence.Three types of flaps involving the gluteal crease based on different terminal branches of the inferior gluteal artery have been described in the literature: the infragluteal flap,4 the inferior gluteal artery perforator (IGAP) flap,5,6 and the inferior gluteal artery myocutaneous flap.7 Many clinicians harvest free flaps from the gluteal crease region for breast reconstruction because of its fatty composition.4-6 Gluteal crease flaps also provide positive aesthetic results for both the breast reconstruction and donor site scar without sacrificing muscle at a donor site. According to the case studies of Scheufler et al8 $(\mathrm{N}=13)$ and Higgins et al's case report, 9 gluteal crease flaps also may be harvested for ischial pressure ulcer coverage.8,9

Two mechanisms contribute to pressure ulcer development: external pressure that compresses blood vessels and friction and shearing forces that tear and injure blood vessels. The sacral pressure ulcer is susceptible to recurrence if the underlying mechanisms are not addressed.In the authors' facility, a local, unilateral, gluteus fasciocutaneous rotation advancement flap is the usual choice for sacral defects. Gluteus fasciocutaneous rotation advancement flap flap surgery is technically easy to perform. However, the gluteus maximus muscle should be partially split to allow for advancement of the flap and tension-free closure, which introduces the potential for gait instability in an ambulatory patient. The derived flap seldom crosses the midline of the gluteal region; a bilateral gluteus maximus myocutaneous advancement flap is needed for larger defects.1

The purpose of this case study is to describe the outcomes of patients in whom a gluteal artery sparing fasciocutaneous flap was used for reconstruction of sacral pressure ulcers.

\section{Methodology:}

The present study was planned in the Department of Plastic Surgery, Pulse Emergency Hospital, Patna, Bihar. Total 11 cases of sacral pressure sore operated from Jan 2017 to Apr 2018 were included in the present study. All the patients were informed consents. The aim and the objective of the present study were conveyed to them. Approval of the institutional ethical committee was taken prior to conduct of this study.

\section{Patients and Methods}

The authors treated and retrospectively analyzed the 11 patients ( 8 men, 3 women; mean age 41 [range 27-71] years old) whose sacral pressure ulcers had been reconstructed using rotating gluteal fasciocutaneous flaps. All patients were bedridden; 1 patient in a vegetative state with a diagnosis of Cerebro vascular accident was referred from a other hospital, 2 patients had pelvic bone fracture on long duration traction, and 2 patients had a history of Cervical injury leading to quadriplegia , and 6 patient have hemiplegia due to spinal injury. The patient summary is shown in Table 1.

\section{Surgical procedure}

Surgical repair of the defect was performed with the patient in a prone position under general anesthesia. The surgical field was sterilized, the sacral pressure ulcer was debrided, and the bony prominence of the sacral bone was removed using an osteotome. The wound then was covered with epinephrine-soaked gauze, and the defect size was measured. An elliptical flap was created from the gluteal crease region; the authors' preference is to harvest the flap from the side closest to the sacral pressure ulcer if the ulcer is not centrally located, according to the recommendations of Scheufler et al8 and Higgins et al.9 The axis of the flap was fashioned along the natural gluteal crease, the length of the flap was determined according to the vertical length of the defect, and the width of the flap was $3-5 \mathrm{~cm}$ less than the horizontal width of the defect so as not to interfere with flap inset as well as to facilitate donor site closure (see Figures 1,2 ). The incision was made along the inferior flap margin to identify the inferior border of the gluteus maximus muscle. The length of the dissected pedicle was determined by the arc of movement of the flap.Care was taken to identify the cutaneous branch from the descending branch of the inferior gluteal artery at the inferior margin of the gluteus maximus muscle. If the descending branch was of suitable size ( $>12 \mathrm{~mm})$, the cutaneous branch was isolated and traced along the descending branch toward the origin of the inferior gluteal artery. If the cutaneous branch was absent or too small, the superior margin of the flap was incised. The incision was carried down to the subfascial level, and subfascial dissection was performed caudally to identify the myocutaneous perforator of the inferior gluteal artery. If the perforator was of adequate size $(>1-2 \mathrm{~mm})$, intramuscular dissection of the 
perforator was performed, and the vessel was traced proximally. The flap then was elevated and transferred to the defect. muscle to fill dead space when needed is raised as separate flap.

An inferior gluteal artery based rotation fasciocutaneous flap was raised, and the superior gluteal artery perforator was preserved; alternatively a superior gluteal artery based rotation fasciocutaneous flap was elevated, and inferior gluteal artery perforator was spared.

After surgery, vital signs were monitored every 4 hours in unstable patients and every 8 hours in stable patients. The incision and dressing were monitored for signs of infection, and the amount of drainage was noted. Wet gauze dressing changes were performed using sterile technique throughout the hospitalization, and patients' positions were changed every 2 hours. Some patients were placed on airfluidized beds to decrease the frequency of patient repositioning. Patients were instructed to lay in the supine position during the day and to remain prone at night for approximately 2 weeks until the flap healed, after which they were discharged to a nursing facility or returned home. Patients were instructed to transition to full supine bed rest 4 weeks after surgery and continue this until wound healing without dehiscence was achieved.

Patients were re-examined and the wound photographed every week in the outpatient department; alternatively, telephone interviews were conducted by the authors' medical staff if the patients did not return for follow-up.

\section{Results and Discussion;}

The average defect size was $110 \mathrm{~cm} 2$ (range 78-134 $\mathrm{cm} 2$ ). The average flap size was $75.8 \mathrm{~cm} 2$ (range 46$111 \mathrm{~cm} 2$ ). Seven (7) flaps were harvested from the left gluteal region and four (4)from the right gluteal region. Although venous congestion commonly caused flaps to become purple and swollen immediately following surgery, all flaps survived completely and achieved wound healing without complications No surgery-related mortality was noted. The longest follow-up was 24 months. No adverse outcomes were noted, but 1 pressure ulcer recurred (patient 2) 5 months after surgery (see Table).

Table 1:

\begin{tabular}{|l|l|l|l|l|l|l|l|}
\hline $\begin{array}{l}\text { Patient } \\
\text { No. }\end{array}$ & Age & Sex & Diagnosis & Location & $\begin{array}{l}\text { Defect } \\
\text { Size }(\mathrm{cm})\end{array}$ & $\begin{array}{l}\text { Flap Size } \\
(\mathrm{cm})\end{array}$ & Details \\
\hline 1 & 27 & M & $\begin{array}{l}\text { Sacral pressure } \\
\text { sore(r) }\end{array}$ & Sacral & $5 \times 5$ & $6 \times 6$ & $\begin{array}{l}\text { Spinal Cord Injury } \\
\text { (Paraplegia ) }\end{array}$ \\
\hline 2 & 46 & M & $\begin{array}{l}\text { Grade IV sacral } \\
\text { pressure sore }\end{array}$ & Sacral & $10 \times 7$ & $11 \times 8$ & $\begin{array}{l}\text { Spinal cord injury } \\
\text { ( Paraplegia ) }\end{array}$ \\
\hline 3 & 49 & M & $\begin{array}{l}\text { Grade IV } \\
\text { sacral sore }\end{array}$ & Sacral & $6 \times 5$ & $7 \times 6$ & $\begin{array}{l}\text { \#D12 with paraplegia anterior } \\
\text { decompression done }\end{array}$ \\
\hline 4 & 71 & F & $\begin{array}{l}\text { Grade IV } \\
\text { sacral sore }\end{array}$ & Sacral & $6 \times 6$ & $7 \times 7$ & CVA \\
\hline 5 & 47 & M & $\begin{array}{l}\text { Sacral sore } \\
\text { (left side) }\end{array}$ & Sacral & $6 \times 7$ & $7 \times 8$ & $\begin{array}{l}\text { subluxation with } \\
\text { Quadriplegia }\end{array}$ \\
\hline 6 & 32 & M & $\begin{array}{l}\text { Grade IV } \\
\text { Sacral Sore }\end{array}$ & Sacral & $11 \times 8$ & $14 \times 10$ & paraplegia \\
\hline 7 & 44 & M & $\begin{array}{l}\text { Grade III } \\
\text { Sacral Sore }\end{array}$ & Sacral & $9 \times 7$ & $12 \times 8$ & Paraplegia \\
\hline 8 & 28 & M & $\begin{array}{l}\text { Grade IV } \\
\text { Sacral Sore }\end{array}$ & Sacral & $11 \times 9$ & $14 \times 10$ & Quadriplegia \\
\hline 9 & 38 & F & $\begin{array}{l}\text { Grade III } \\
\text { Sacral sore }\end{array}$ & Sacral & $8 \times 6$ & $10 \times 14$ & Pelvic Bone fracture \\
\hline 10 & 48 & M & $\begin{array}{l}\text { Grade IV } \\
\text { Sacral Sore }\end{array}$ & Sacral & $12 \times 9$ & $14 \times 10$ & Paraplegia \\
\hline 11 & 63 & F & $\begin{array}{l}\text { Grade III } \\
\text { Sacral Sore }\end{array}$ & sacral & $7 \times 5$ & $10 \times 8$ & Pelvic Bone Fracture \\
\hline
\end{tabular}


Figure 1

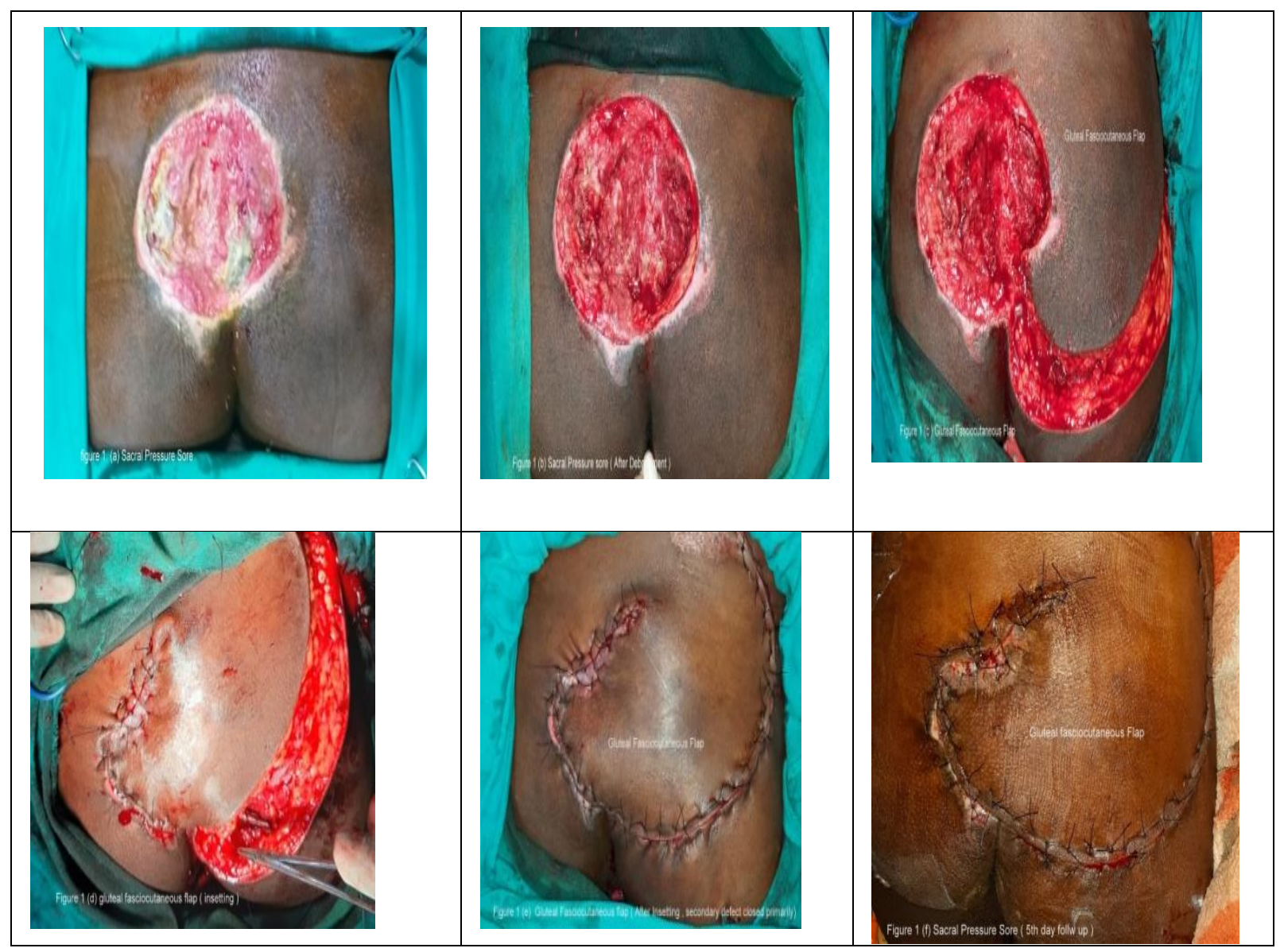

Figure 2

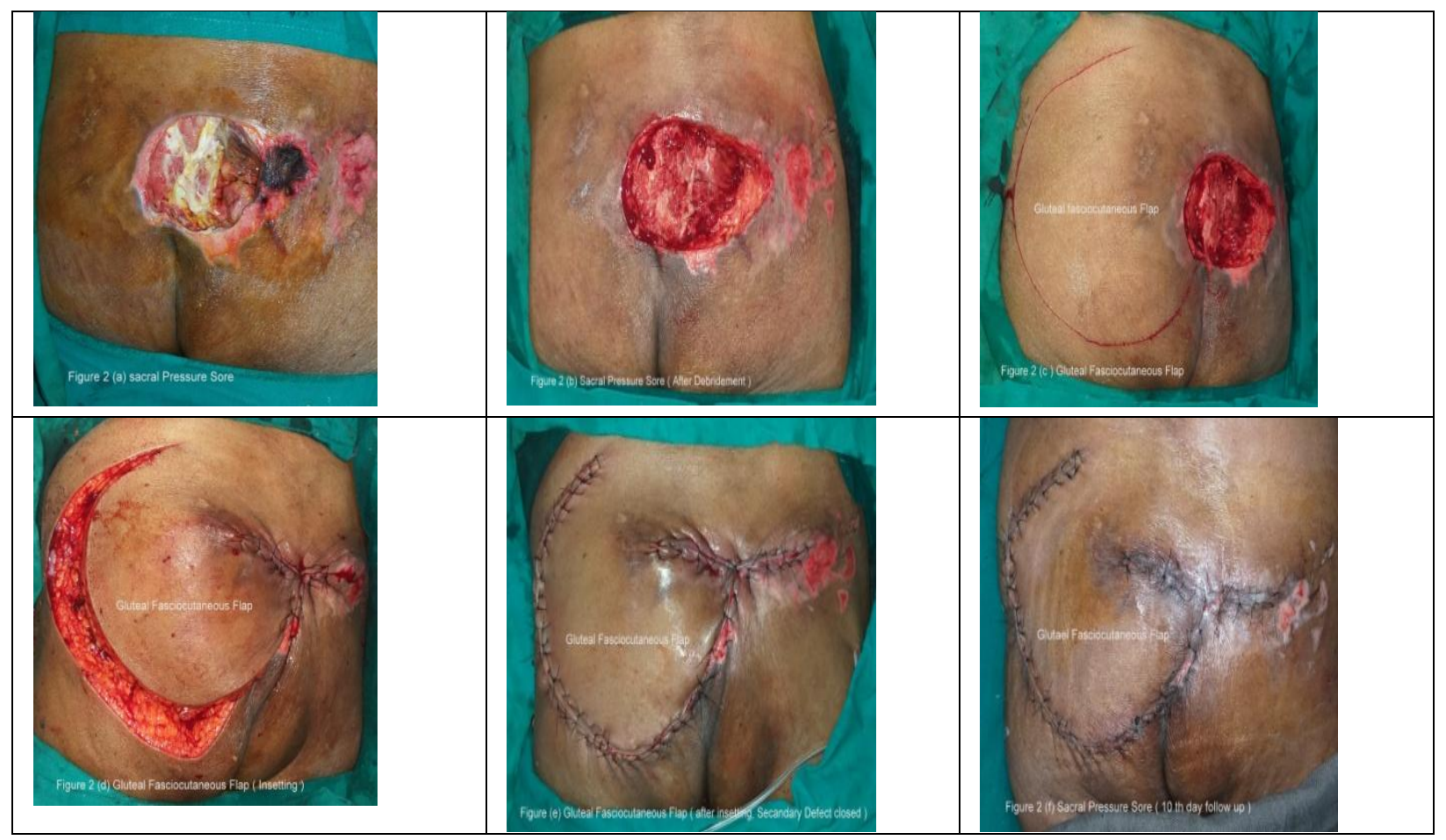

Figure 3 


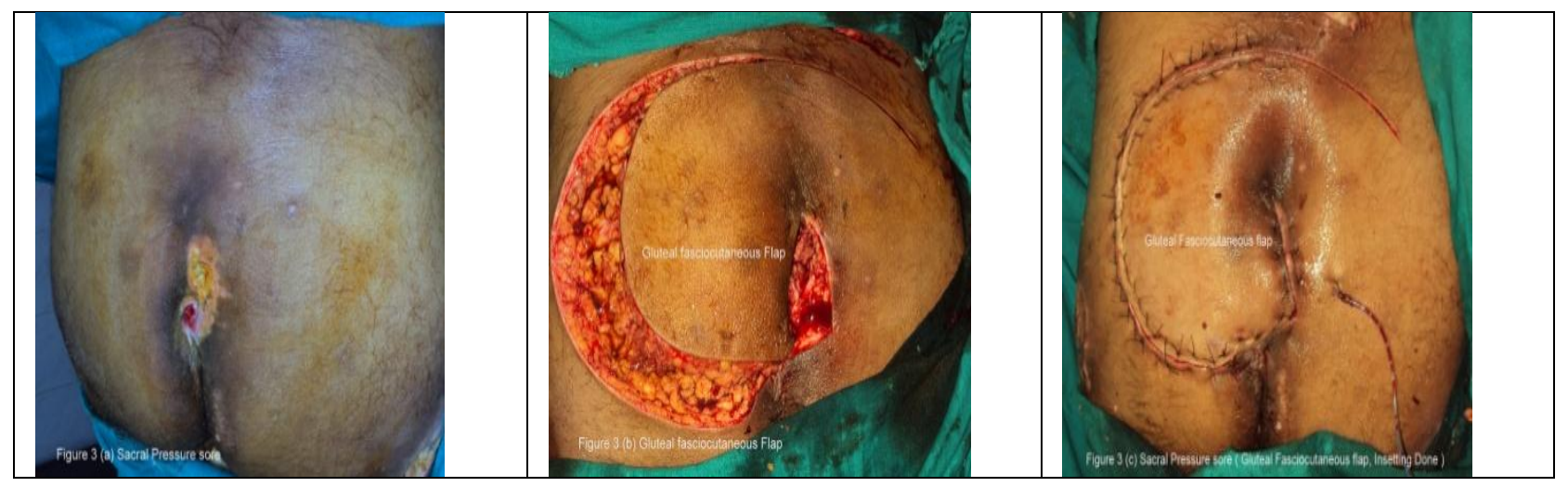

Figure 4
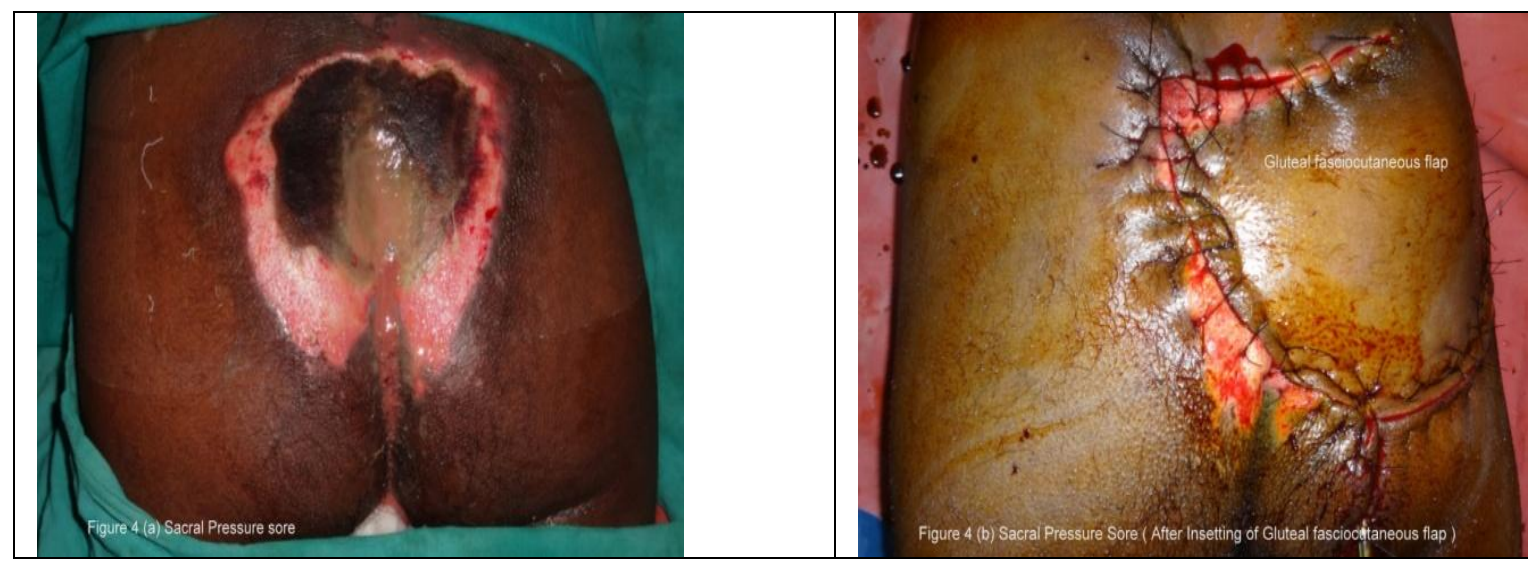

Pre-operative preparation is the most important factor for maintaining a healed wound after flap closure. Paraplegic patients are especially prone to postoperative recurrence of their sores. The pedicled superior gluteal artery perforator flap, being a fasciocutaneous flap, lacks muscle 'cushioning' and continued pressure over it will lead to recurrence of the sore. Pre-operative pressure relief protocols and surfaces as well as ensuring patient compliance are therefore mandatory before planning a superior gluteal artery perforator flap.

Physical medicine and rehabilitation services may also be involved. Adequate home and social support should be ensured. We also recommend the following guidelines for ensuring flap success and preventing recurrence: (i) strict pre-operative as well as postoperative control of medical conditions such as diabetes mellitus and hypertension; (ii) good preoperative mapping of perforator vessels using a Doppler probe; (iii) adequate intra-operative debridement of the sore with complete bursectomy; (iv) maintaining aprone position for 2 weeks postoperatively; and (v) pre-operative and postoperative optimisation of nutrition.

The limited number of patients and short period in follow-up are the drawbacks of this study. In fact, practicing a regular follow-up in bed-ridden patients is not easy and measuring the thickness of gluteus muscle after 6 months postoperatively has clinical significance.

Managing sacral pressure ulcers is a common task for reconstructive surgeons. Several types of flaps have been developed to cover sacral pressure ulcers.1,1114 Coskunfirat et al13 presented the largest case series in the literature, with 32 gluteal artery perforator flaps for pressure ulcer reconstruction. The perforator flap provides a reliable fasciocutaneous flap for sacral pressure ulcer closure and spares the underlying muscle. However, according to Coskunfirat et al's13 study, unlike other gluteal perforator flaps, the unpredictable perforator artery location often necessitates a change of flap design intraoperatively.

Harvesting the flap is technically demanding. Creating the gluteal fasciocutaneous flap flap involves a 
dissection of the perforator penetrating the gluteus maximus muscle underneath the piriformis muscle.. Using the flap from the gluteal crease has several advantages.5-9 First, the constant circulation always ensures successful flap harvesting from the gluteal crease despite having only tiny $(<1-2 \mathrm{~mm})$ perforators. Coskunfirat et al13 suggest this flap can be used as a primary choice in sacral pressure ulcer coverage; Doppler has been found to be unreliable in detecting perforators in the gluteal region, and the perforator is typically identified directly through subfascial dissection.13 Second, according to casecontrol studies,7,8 the infragluteal perforator flap minimizes donor-site morbidity by sparing the gluteal muscles and eliminating the need for primary closure of the donor site; the resulting scar avoids maximal pressure zones over bony prominences. This is beneficial for ambulatory patients for walking or sitting; however, most of the patients in the current study were bedridden. Third, the gluteal fasciocutaneous flap minimizes donor site morbidity by sparing the gluteal muscle and primary closure of the donor site, leaving a scar that avoids maximal pressure zones over bony prominences and allowing the scar to remain well hidden in the natural gluteal crease. 8 Fourth, in the event of a recurrent ulcer or flap failure, the flap can be raised from an area other than the previous operative site; this technique provides a secondary option for salvage in such cases, as described in the case control study of Higgins et al.9

The major disadvantage of this flap is vascular variation. According to a large case series $(\mathrm{N}=$ 118),14 the descending branch of the inferior gluteal artery is present with variable prevalence.8,14 In the Windhofer et al14 study, the descending branch was present in $91.5 \%$ of patients. When the descending branch was absent, the cutaneous branch came from the medial or lateral circumflex femoral artery or as a perforator of the deep artery of the thigh.

Hip contracture occurs frequently in the long-term bedridden patient.15 This increases wound tension over the donor site and increases the chance of wound dehiscence. In the current patient series, wound dehiscence of 1 donor site occurred in a patient with hip contracture. In addition, hip flexion might cause undue tension on the flap pedicle, requiring caution in a patient with hip contracture. During the postoperative care period, the caregiver should prevent overflexion of the hip joint for at least
2 weeks. An added consideration is the relatively technical nature of flap creation owing to the demands of intramuscular dissection.

Using the gluteal perforator flap is controversial because published anatomical studies state the blood supply to the gluteal skin is inadequate. In their case control study, Ahmadzadeh et al16 performed a detailed dissection of the gluteal region and determined the vascular territory of a single perforator from the inferior gluteal artery is approximately $24 \mathrm{~cm} 2$. However, Koshima et al's17 case-control study demonstrated a flap in the gluteal region can be nourished even by a single perforator; similarly, Nojima et al's18 case-control study reported a vascular territory of mean size of $15 \mathrm{~cm} \mathrm{x}$ $12 \mathrm{~cm}$ in the superior gluteal artery perforator flap can be nourished using single perforator with the dye injection method. Skin in the gluteal region also has been shown to be richly vascularized with perforators connected by long and voluminous subcutaneous anastomoses.18 In light of these factors, the authors of the current study concluded the determinant factor for flap size is whether the donor site can be primarily closed.

Good results have been reported using advancement island flap, split flap, and rotation flaps including gluteus maximus muscular flap and myocutaneous flap for sacral PUs reconstruction [19]. The muscle is thought to provide a better "tissue buffer" over the sacrum for continuous external tension to effectively prevent recurrence and for better ability in obliterating any dead space or healing tissue infection [20-22]. However, a recent retrospective study indicated that musculocutaneous flaps are as good as fasciocutaneous flaps in the reconstruction of PUs and there were no significant differences in early complications, postoperative morbidity, or ulcer recurrence between these two kinds of flap [23].

The superior gluteal artery perforator-based fasciocutaneous flap and gluteus maximus myocutaneous flap were both applied in this case series. Optimal outcomes were consistently obtained with no difference in the occurrence of postoperative complication or recurrence of PU.

In this case series, the fasciocutaneous flap was harvested without well-known perforators during the surgery, while reliable outcomes were also obtained and the well vascularized flap could be performed without microsurgical dissection. Similarly, Demiryilmaz et al. [23] successfully treated 
sacrococcygeal pilonidal sinus disease with bilateral fasciocutaneous $V-Y$ advancement flap following total excision. Han et al. [19] closed the sacral PUs with bilateral combined $\mathrm{V}-\mathrm{Y}$ fasciocutaneous advancement and gluteus maximus muscle rotational flaps. Hsiao and Chuang [25] reported their successful experience of reconstructing sacral PUs with dual-dermal-barrier fashion flaps. Prado et al. [26] treated sacral defects with "double-A" bilateral flaps based on perforators.

\section{Conclusion:}

The perforator-preserving gluteal artery-based rotation fasciocutaneous flap is a reliable, reusable flap that provides rich vascularity facilitating wound healing and accommodating the difficulties of pressure sore reconstruction

The data generated from the present study concludes that the modified method we proposed is relatively simple and easy for reconstructing sacral sores, provides sufficient padding, and has little muscle donor-site morbidity. Once sufficient padding is established in cases like this, a takeaway from this report would be to study the recurrence rates compared with the classic fasciocutaneous flap.

\section{References:}

1. Ohjimi $H$, Ogata $K$, Setsu $Y$, Haraga I. Modification of the gluteus maximus $\mathrm{V}-\mathrm{Y}$ advancement flap for sacral ulcers: the gluteal fasciocutaneous flap method. Plast Reconstr Surg. 1996;98(7):1247-1252.

2. Wong $\mathrm{CH}$, Tan $\mathrm{BK}$, Song $\mathrm{C}$. The perforatorsparing buttock rotation flap for coverage of pressure sores. Plast Reconstr Surg. 2007;119 (4):1259-1266.

3. Balakrishnan C, Brotherston TM. Transverse lumbar flap for sacral bed sores. Plast Reconstr Surg. 1992;89(5):998-999.

4. Papp C, Windhofer C, Gruber S. Breast reconstruction with the fasciocutaneous infragluteal free flap ( $\mathrm{FCl})$. Ann Plast Surg. 2007;58(2):131-136.

5. Beshlian KM, Paige KT. Inferior gluteal artery perforator flap breast reconstruction. Am J Surg. 2008;195(5):651-653.

6. Allen RJ, Levine JL, Granzow JW. The in-thecrease inferior gluteal artery perforator flap for breast reconstruction. Plast Reconstr Surg. 2006;118(2):333-339

7. Hurwitz DJ. Closure of a large defect of the pelvic cavity by an extended compound myocutaneous flap based on the inferior gluteal artery. $\mathrm{Br} J$ Plast Surg. 1980;33(2):256-261.

8. Scheufler O, Farhadi J, Kovach SJ, Kukies S, Pierer G, Levin LS, Erdmann D. Anatomical basis and clinical application of the infragluteal perforator flap. Plast Reconstr Surg. 2006;118(6):13891400.

9. Higgins JP, Orlando GS, Blondeel PN. Ischial pressure sore reconstruction using an inferior gluteal artery perforator (IGAP) flap. Br J Plast Surg. 2002;55(1):83-85.

10. Shea JD. Pressure sores: classification and management. Clin Orthop Relat Res. 1975;(112):89-100.

11. Heywood AJ, Quaba AA. Modified gluteus maximus V-Y advancement flaps. Br J Plast Surg. 1989;42(3):263-265.

12. Lee HB, Kim SW, Lew DH, Skin KS. Unilateral multilayered musculocutaneous $\mathrm{V}-\mathrm{Y}$ advancement flap for the treatment of pressure sore. Plast Reconstr Surg. 1997;100(2):340-345.

13. Coskunfirat OK, Ozgentas HE. Gluteal perforator flaps for coverage of pressure sores at various locations. Plast Reconstr Surg. 2004;113(7): 2012-2017.

14. Windhofer C, Brenner E, Moriggl B, Papp C. Relationship between the descending branch of the inferior gluteal artery and the posterior femoral cutaneous nerve applicable to flap surgery. Surg Radiol Anat. 2002;24(5):253-257.

15. Vanwanseele B, Lucchinetti E, Stüssi E. The effects of immobilization on the characteristics of articular cartilage: current concepts and future directions. Osteoarthritis Cartilage. 2002;10(5):408-419.

16. Ahmadzadeh R, Bergeron L, Tang M, Morris SF. The superior and inferior gluteal artery perforator flaps. Plast Reconstr Surg. 2007;120 (6): 1551-1556.

17. Koshima I, Moriguchi T, Soeda S, Kawata S, Ohta $S$, Ikeda A. The gluteal perforator-based flap for repair of sacral pressure sores. Plast Reconstr Surg. 1993;91(4):678-683.

18. Nojima K, Brown SA, Acikel C, Arbique G, Ozturk $S$, Chao J, et al. Defining vascular supply and territory of thinned perforator flaps: part I. Anterolateral thigh perforator flap. Plast Reconstr Surg. 2005;116(1):182-193.

19. Han HH, Choi EJ, Moon SH, Lee YJ, Oh DY. Combined $V-Y$ fasciocutaneous advancement and gluteus maximus muscle rotational flaps for 
Dr. Shyam Kumar Satyapal, International Journal of Medical and Biomedical Studies (IJMBS)

treating sacral sores. Biomed Res Int. 2016;2016:8714713. [PMC free article] [PubMed] [Google Scholar]

20. Wong TC, Ip FK. Comparison of gluteal fasciocutaneous rotational flaps and myocutaneous flaps for the treatment of sacral sores. Int Orthop. 2006;30:64-67. doi: 10.1007/ s00264-005-0031-5. [PMC free article] [PubMed] [CrossRef] [Google Scholar]

21. Therattil PJ, Pastor C, Granick MS. Sacral pressure ulcer. Eplasty. 2013;13:ic18. [PMC free article] [PubMed] [Google Scholar]

22. Maslauskas $K$, Samsanavicius $D$, Rimdeika $R$, Kaikaris V. Surgical treatment of pressure ulcers: an 11-year experience at the Department of Plastic and Reconstructive Surgery of Hospital of Kaunas University of medicine. Medicina (Kaunas) 2009;45:269-275. [PubMed] [Google Scholar]

23. Thiessen FE, Andrades $\mathrm{P}$, Blondeel PN, Hamdi $\mathrm{M}$, Roche $N$, Stillaert $F$, et al. Flap surgery for pressure sores: should the underlying muscle be transferred or not? J Plast Reconstr Aesthet Surg. 2011;64:84-90. doi: 10.1016/j.bjps.2010.03.049. [PubMed] [CrossRef] [Google Scholar]

24. Demiryilmaz I, Yilmaz I, Peker K, Celebi F, Cimen $\mathrm{O}$, Isik A, et al. Application of fasciocutaneous $\mathrm{V}$ $Y$ advancement flap in primary and recurrent sacrococcygeal pilonidal sinus disease. Med Sci Monit. 2014;20:1263-1266. doi: 10.12659/MSM. 890752. [PMC free article] [PubMed] [CrossRef] [Google Scholar]

25. Hsiao YC, Chuang SS. Dual-dermal-barrier fashion flaps for the treatment of sacral pressure sores. J Plast Surg Hand Surg. 2015;49:3-7. doi: 10.3109/2000656X.2013.792269. [PubMed] [CrossRef] [Google Scholar]

26. Prado A, Ocampo C, Danilla S, Valenzuela G, Reyes S, Guridi R. A new technique of "double-a" bilateralflapsbased on perforators for the treatment of sacral defects. Plast Reconstr Surg. 2007;119:1481-1490. doi: 10.1097/01.prs. 0000 256052.84466.de. [PubMed] [CrossRef] [Google Scholar] 